\title{
Does the advantage of the upper part of words occur at the lexical level?
}

\author{
Manuel Perea $\cdot$ Montserrat Comesaña $\cdot$ Ana P. Soares
}

Published online: 6 July 2012

(C) Psychonomic Society, Inc. 2012

\begin{abstract}
Several recent studies have shown that the upper part of words is more important than the lower part in visual word recognition. Here, we examine whether or not this advantage arises at the lexical or at the letter (letter feature) level. To examine this issue, we conducted two lexical decision experiments in which words/pseudowords were preceded by a very brief (50ms) presentation of their upper or lower parts (e.g., ronoral_general or yellesal-general). If the advantage for the upper part of words arises at the letter (letter feature) level, the effect should occur for both words and pseudowords. Results revealed an advantage for the upper part of words, but not for pseudowords. This suggests that the advantage for the upper part of words occurs at the lexical level, rather than at the letter (or letter feature) level.
\end{abstract}

Keywords Visual word identification - Lexical decision . Computational models

The front end of any computational model of visual word recognition has to specify in detail not only the word level,

\author{
M. Perea \\ ERI Lectura, Universitat de València, \\ Valencia, Spain

\section{Perea $(\bowtie)$} \\ Departamento de Metodología, Facultad de Psicología, \\ Universitat de València, \\ Av. Blasco Ibáñez, 21, \\ 46010 Valencia, Spain \\ e-mail: mperea@uv.es \\ M. Comesaña $\cdot$ A. P. Soares \\ Escola de Psicologia, Universidade do Minho, \\ Braga, Portugal
}

but also the letter and letter feature levels. For the sake of parsimony, current implementations of these models assume that each letter feature is equally important in activating letter representations - usually employing the simplified uppercase font designed by Rumelhart and Siple (1974; see, e.g., Coltheart, Rastle, Perry, Ziegler, \& Langdon, 2001; Davis, 2010; Grainger \& Jacobs, 1996; McClelland \& Rumelhart, 1981). Here, we study the validity of this assumption by examining the role of the upper/lower parts of words and pseudowords.

In his influential book The Psychology and Pedagogy of Reading, Huey (1908/1968) claimed that "the upper part of a letter or word is obviously more important for perception than is the lower half" (p. 65). As an illustration, Huey presented a text in which only the upper part of the words was kept and another text in which only the lower part of the words was kept (see Fig. 11 in Huey, 1908/1968). Although no data were reported, it is evident that the text in which only the upper part of words was kept was easier to read than the text in which only the lower part of words was kept. To explain the bias for the upper part of words, Huey argued that "it is due to ... the words being better differentiated there than below" (p. 65). ${ }^{1}$ However, this reasoning does not shed much light on the locus of the effect. The bias for the upper part of words could occur (1) at the letter level (e.g., there could be more critical information at the top of the letters), (2) at the lexical level, based on individual letters (e.g., in terms of an interaction of letter representations and lexical representations), or (3) at the lexical level on the basis of whole-word representations that are used by the

\footnotetext{
${ }^{1}$ Similarly, in the context of books on "speed reading," it has been claimed that "human beings easily recognize or "read" alphabet characters simply by seeing the top half of the letters" (Wechsler \& Bell, 2005 , p. 62); no citations were provided.
} 
lexical system - not based on individual letters (i.e., the word shape hypothesis). To our knowledge, only two (recent) studies have examined this issue in visual word recognition (Blais et al., 2009; Perea, Comesaña, Soares, \& Moret-Tatay, 2012). Blais et al. employed an image classification technique, the bubbles technique, with lowercase words. ${ }^{2}$ Blais et al. found that "the upper portion of the letters contains more significant voxels than the lower portion. . . . $94 \%$ of the significant pixels falling on letter extensions were located on the ascenders, further supporting the bias for the upper part of words" (p. 6). Likewise, Perea et al. (2012, Experiment 2) found that masked repetition priming effects were greater when the primes (in lowercase) preserved their upper part than when the primes preserved their lower part (e.g., metrn-METRO vs. hntel-METRO greater

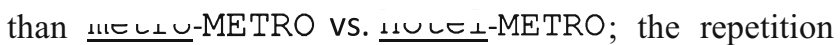
priming effects were 43 and $24 \mathrm{~ms}$, respectively). Furthermore, the magnitude of masked repetition priming for the primes that preserved their upper part was close (only $5 \mathrm{~ms}$ slower) to that of intact primes (metro-METRO vs. hotel-METRO). Perea et al. (2012) also examined whether this advantage occurred with uppercase words. Again, they found greater effects when uppercase primes preserved their upper part than when uppercase primes preserve their lower

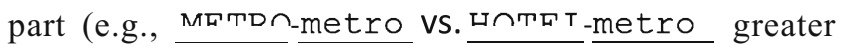
than priming effects were 36 and $15 \mathrm{~ms}$, respectively); nonetheless, the size of the repetition priming effect was smaller than with lowercase primes. Taken together, the findings from Blais et al. and Perea et al. (2012), using different languages and tasks, reveal that there is an advantage for the upper part of the words during visual word recognition.

The critical question under study in the present article is whether the advantage for the upper part of words occurs at the letter (letter feature) level or whether its locus is at a higher processing level - the lexical level, in particular. The rationale of the present series of experiments is the following: If the advantage for the upper part of words has its locus at the letter (or letter feature) level (e.g., on the basis of the peculiarities of the Roman alphabet), one would expect this advantage to appear not only for the upper part of words, but also for the upper part of letters or the upper part of pseudowords. However, using the bubbles technique (i.e., the same technique employed by Blais et al., 2009), Fiset et al. (2008) failed to find any bias for the upper part of lowercase or uppercase letters. Similarly, Fiset et al. (2008) showed that

\footnotetext{
$\overline{2}$ This technique employs Gaussian blobs (i.e., bubbles) as windows to partially allow the participant to see a target stimulus that is mostly masked by a gray mask. The locations of the bubbles are randomly selected on a trial-by-trial basis; they also vary within a trial such that the stimulus's parts available to the participants vary through time (see Fig. 1 in Blais et al., 2009).
}

even across time, there is no bias for the upper part of single letters. Blais et al. concluded that "intriguingly, this bias for the upper portion of the letters appears to be restricted to the case where letters are presented within the context of words" and "letter representations may be slightly different for isolated letters and for letters in words" (p. 6). To further explore this issue, in the present article, we examine whether the advantage for the upper part of words can also be obtained with (orthographically legal) pseudowords (i.e., letter strings rather than isolated letters). If the advantage for the upper part of letter strings occurs for both words and pseudowords, this would support the view that the "bias for the upper part of words" occurs at an early letter (or letter feature) level. This outcome would imply that models of visual word recognition should be modified to assign more weight to the upper part of letters. Alternatively, if the advantage for the upper part of letter strings occurs for words but not for pseudowords, the effect would not occur at a letter (or letter feature) level but, rather, at the lexical level. At the theoretical level, this outcome would suggest that both the lower and the upper portions of letters are equally important in activating letter representations, as predicted by the front end of current models of visual word recognition (or the data with isolated letters from Fiset et al., 2008). We should note here that the experiments of Blais et al. and Perea et al. (2012) were not designed to examine the effects with pseudowords. First, Blais et al. did not employ pseudowords in their experiment. Second, Perea et al. (2012) did use pseudowords in their masked priming experiments but failed to obtain any priming effects with pseudowords. Nonetheless, masked repetition priming effects for pseudowords tend to be small and inconsistent (see Forster, 1998; Perea, Gomez, \& Fraga, 2010). Note that the presence of masked priming effects for words, but not for pseudowords, is the basic reason why masked priming effects are assumed to be lexical (see Forster, 1998; Forster \& Davis, 1984).

To study whether the advantage for the upper part of words has a lexical or a letter (letter feature) origin, we employed the lexical decision task (i.e., "does the letter string form a word or not?") combined with a delayedsegment technique. The delayed-segment technique is parallel in nature to the delayed-letter technique employed by Lee, Rayner, and Pollatsek (2001, 2002) and Carreiras, Gillon-Dowens, Vergara, and Perea (2009). The only difference is that instead of delaying the presentation of one or two letters for a brief period, we delay either the upper or the lower part of the letter string. More specifically, in the delayed-segment technique, the stimulus is preceded by a brief (50-ms) presentation of its lower or upper part, as illustrated in Fig. 1. As in the delayed-letter technique, we also include a baseline, nondelay condition in which the letter string is preceded by itself. Importantly, unlike masked 
Fig. 1 Illustration of the delayed-segment technique. A given word/pseudoword is briefly $(50 \mathrm{~ms})$ preceded by itself, its upper part, or its lower part

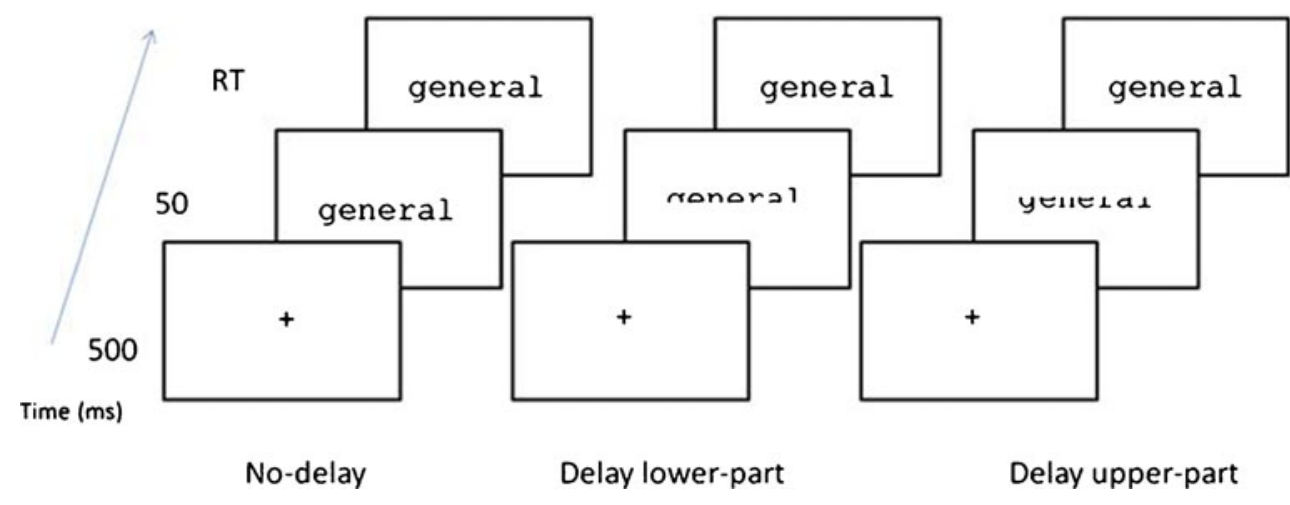

priming lexical decision experiments, the effects obtained with a delayed-letter technique occur for both words and pseudowords (see Carreiras et al., 2009). Thus, the letter/ segment technique may be more sensitive than masked priming for capturing the effects with pseudowords in a lexical decision experiment.

\section{Overview of the experiments}

We conducted two lexical decision experiments with a delayed-segment technique. The main goal was to examine the nature of the advantage for the upper part of words in visual word recognition. If the advantage for the upper part of letters occurs with words, but not with pseudowords, this would strongly suggest that this advantage is not due to the letter (letter feature) level but, instead, occurs later in processing. We also examined whether the effect of delay would be modulated by word frequency. Perea et al. (2012) found a comparable priming advantage for the upper part of words for high- and low-frequency words in a masked priming technique. If one uses the additive-factor logic method (Sternberg, 1998), the additivity between priming and frequency suggests that the bias for the upper part of words may occur quite early in processing. We believe that it is important to examine whether this pattern of additivity also occurs when the delayed-segment technique is used.

\section{Experiment 1}

In Experiment 1, we added an extra manipulation. In their masked priming experiments, Perea et al. (2012) found an advantage for the upper part of words not only for lowercase words, but also for uppercase words. Importantly, the effects were greater for lowercase words than for uppercase words. In order to shed more light on the nature of the advantage for the upper part of words, and also evaluate the potential similarities/differences between the masked priming and the delayed-segment techniques, we believe that it is important to examine whether the same pattern holds with the delayed-segment technique.

Method

Participants Twenty-four psychology undergraduates at the University of Minho (Portugal) participated in the experiment in exchange for course credit (mean age $=21$ years, $S D=4.2$ ). All of them were native speakers of European Portuguese and had normal or corrected-to-normal vision.

Materials We selected a set of 240 words from the European Portuguese database (Soares et al., 2010). Half of the words were of high frequency $(M=129.8$ occurrences per million, range $=51.8-249 ;$ mean number of letters $=5.8$, range $=5-8$; mean number of orthographic neighbors $=1.7$, range $=0-9$ ), and the other half were of low frequency $(M=3.1$ occurrences per million, range $=0.18-13$; mean number of letters $=5.8$, range $=5-8$; mean number of orthographic neighbors $=2.0$, range $=0-8)$. In order to avoid orthographic marks, none of the words had diacritics (i.e., words like lingua [language]). For each word in lowercase/uppercase, we created three potential segments: (1) The word was preceded by itself for $50 \mathrm{~ms}$ (baseline nondelay condition; e.g., general-general; GENERAL_GENERAL); (2) the word was preceded by itself for $50 \mathrm{~ms}$, except that the lower part of the word was missing (delay-lower condition; reneral-general; reNTED A _GENERAL); and (3) the word was preceded by itself for $50 \mathrm{~ms}$, except that the upper part of the word was missing (delay-upper condition; yented L-general; GeINEKLSL-GENERAL). The criterion for deciding the upper versus lower part of the letter strings was defined in terms of $y$-coordinates and, more specifically, on the basis of the horizontal line of the lowercase letter "e" in 18-point Courier New font (i.e., the upper/lower portion of each word was defined as just above/below this line). We also created a set of 240 pseudowords of five to eight letters $(M=5.8)$ for the purposes of the lexical decision task. These pseudowords were 
orthographically legal and had been created by changing one or two letters from Portuguese words that were not included in the experimental word set (e.g., tordomo, esvoto, falanha, laide). The manipulation of the pseudoword trials was the same as that for the word trials. Six lists of counterbalanced materials were created, so that participants saw each target word (or pseudoword) in only one of the conditions (general_general, GENERAL_GENERAL ronora 1_general; ratront_GENERAL; yeuELa1_ general, GeIveraL-GENERAL ). The assignment of the stimuli to the experimental conditions was counterbalanced across participants. The complete set of stimuli is available in the Appendix.

Procedure Participants were tested individually in a soundproof booth. DMDX software was employed to present the stimuli and collect the responses (Forster \& Forster, 2003). On each trial, a fixation point ("+") appeared at the center of the screen for $500 \mathrm{~ms}$. This fixation point was followed by a word or a pseudoword that remained on the screen until the participant's response or until 2,500 ms had elapsed. On one third of the trials, the lower part of the stimuli was delayed for $50 \mathrm{~ms}$ (delay-lower condition; e.g., ronoral_general); on another one third of the trials, the upper part of the stimuli was delayed for $50 \mathrm{~ms}$ (delay-upper condition; e.g., yenesal-general); and on the other third of trials, the entire stimulus was preceded by itself for $50 \mathrm{~ms}$ (baseline condition; general_general) (see Fig. 1). Response times were measured from the onset of the target stimulus. Participants were told that they would see a string of letters on the screen, and they were asked to press the "yes" button if they thought the letter string was a real Portuguese word and press the "no" button if they thought the letter string was not a word. Participants were instructed to make this decision as quickly and as accurately as possible. Each participant received a different, randomized order of trials. Before the experimental phase, there were 20 practice trials with the same manipulation as that on the experimental trials. The experimental session lasted for around 15-20 min.

Results and discussion

Incorrect responses $(5.8 \%$ and $7.2 \%$ of word and pseudoword trials, respectively) and lexical decision times less than $250 \mathrm{~ms}$ or greater than $1,500 \mathrm{~ms}$ (less than $0.6 \%$ and $1.7 \%$ of word and pseudoword trials, respectively) were excluded from the latency analyses. The mean lexical decision times for correct responses and error rates are displayed in Table 1. For both word and pseudoword trials, the critical comparison is the delay of the lower part versus the delay of the upper part. Nonetheless, for the sake of completeness, we also include the nondelayed conditions in the analyses of variance (ANOVAs). Specifically, for word trials, ANOVAs based on the participant $\left(F_{1}\right)$ and item $\left(F_{2}\right)$ response latencies and error rates were conducted on the basis of a 2 (word frequency: low, high) $\times 2$ (case: lowercase, uppercase) $\times 3$ (segment delay: no delay, delay-upper, delaylower) $\times 6$ (list: $1,2,3,4,5,6)$ design. The statistical analyses for pseudoword trials were the same as those for word trials, except for the absence of word frequency as a factor. List was included as a factor in all the statistical analyses to partial out the variability caused by the counterbalanced lists (see Pollatsek \& Well, 1995).

Table 1 Mean lexical decision times (RTs, in milliseconds; with standard deviations) and percentages of errors (ERs) for word and pseudoword targets in Experiment 1

\begin{tabular}{|c|c|c|c|c|c|c|}
\hline & \multicolumn{4}{|l|}{ Words } & \multirow{2}{*}{\multicolumn{2}{|c|}{ Pseudowords }} \\
\hline & \multicolumn{2}{|c|}{ Low Frequency } & \multicolumn{2}{|c|}{ High Frequency } & & \\
\hline & RT & ER & RT & ER & RT & ER \\
\hline \multicolumn{7}{|l|}{ Lowercase } \\
\hline No delay & $596(13)$ & $10.1(1.7)$ & $540(16)$ & $1.3(0.5)$ & $693(21)$ & $6.9(1.4)$ \\
\hline Delay-lower & $609(14)$ & $8.1(1.6)$ & $543(14)$ & $1.9(0.6)$ & $718(23)$ & $5.8(1.2)$ \\
\hline Delay-upper & $629(15)$ & $8.6(1.7)$ & $551(12)$ & $1.0(0.4)$ & $715(21)$ & $8.5(2.0)$ \\
\hline D.-lower vs. no delay & 13 & -1.9 & 3 & 0.6 & 25 & -1.1 \\
\hline D.-upper vs. no delay & 33 & -1.4 & 11 & -0.3 & 22 & 1.6 \\
\hline \multicolumn{7}{|l|}{ Uppercase } \\
\hline No delay & $624(16)$ & $10.0(1.4)$ & $531(14)$ & $1.5(0.6)$ & $731(26)$ & $7.5(1.6)$ \\
\hline Delay-lower & $651(17)$ & $12.8(2.3)$ & $567(12)$ & $2.1(0.6)$ & $749(25)$ & $7.9(1.9)$ \\
\hline Delay-upper & $671(16)$ & $9.9(1.5)$ & $576(12)$ & $1.9(0.6)$ & $752(25)$ & $6.5(2.0)$ \\
\hline D.-lower vs. no delay & 27 & 2.8 & 36 & 0.6 & 18 & 0.4 \\
\hline D.--upper vs. no delay & 47 & -0.1 & 45 & 0.4 & 21 & -1.0 \\
\hline
\end{tabular}


Word data The ANOVA on the response times showed that, on average, response times to high-frequency words were $79 \mathrm{~ms}$ shorter than the response times to low-frequency words, $F_{1}(1,18)=262.42, M S E=1,694, p<.001$; $F_{2}(1,224)=158.7, M S E=16,973, p<.001$, and that, on average, words in lowercase were responded to $25 \mathrm{~ms}$ faster than the words in uppercase, $F_{1}(1,18)=53.28$, $M S E=869, p<.001 ; F_{2}(1,224)=60.49, M S E=4,911$, $p<.001$. The advantage of lowercase versus uppercase words was greater for low-frequency than for high-frequency words ( 37 vs. $13 \mathrm{~ms}$ ), as deduced from the interaction between word frequency and case, $F_{1}(1,18)=7.36, M S E=1,285$, $p<.015 ; F_{2}(1,224)=13.43, M S E=4,911, p<.001$.

The main effect of delay was also significant, $F_{1}(2,36)=$ $33.89, M S E=822, p<.001 ; F_{2}(2,448)=28.56, M S E=$ $5,344, p<.001$, and this effect was greater for lowercase words than for uppercase words, as deduced from the interaction between delay and case, $F_{1}(2,36)=7.65, M S E=591$, $p<.003 ; F_{2}(2,448)=6.34, M S E=5,216, p<.003$. More specifically, for lowercase words, we found a significant effect of delay, $F_{1}(2,36)=9.70, M S E=598, p<.001$; $F_{2}(2,454)=4.71, M S E=5,075, p<.01$. This effect showed that response times to lowercase words were longer when the upper portion of the words was briefly delayed (e.g., general-general) than when the lower portion was briefly delayed (e.g., general-general) (a 14-ms difference), $F_{1}(1,18)=8.66, M S E=518, p<.01$; $F_{2}(1,227)=5.16, M S E=5,215, p<.025$, and when there was no delay (a 22-ms difference), $F_{1}(1,18)=25.80$, $M S E=440, p<.001 ; F_{2}(1,227)=9.31, M S E=4,614, p<$ .004 . In contrast, the advantage for the nondelayed condition over the condition in which the lower portion of the words was briefly delayed was not significant $(8 \mathrm{~ms}), F_{1}(1,18)=1.87$, $M S E=836, p=.19 ; F_{2}<1$. For uppercase words, we also found a significant effect of delay, $F_{1}(2,36)=32.63, M S E=$ $814, p<.001 ; F_{2}(2,450)=26.58, M S E=6,139, p<.001$. This reflected the fact that lexical decision times were longer for words in which their upper part was briefly delayed than for the words in which their lower part was briefly delayed (a 15$\mathrm{ms}$ difference), $F_{1}(1,18)=5.72, M S E=930, p<.03$; $F_{2}(1,225)=4.18, M S E=6,348, p<.05$, and for the words in the nondelay condition (a 46-ms difference), $F_{1}(1,18)=71.92$, $M S E=709, p<.001 ; F_{2}(1,227)=50.28, M S E=5,808, p<$ .001 . In addition, unlike lowercase words, the advantage for the nondelayed condition over the condition in which the lower part was briefly delayed was sizable $(31 \mathrm{~ms}), F_{1}(1,18)=29.08$, $M S E=804, p<.001 ; F_{2}(1,225)=23.77, M S E=6,413, p<$ .001 . The other interactions did not approach significance.

The ANOVA on the error data reflected only a main effect of word frequency: Participants committed more errors to low-frequency words than to high-frequency words, $F_{1}(1,18)=66.51, M S E=75.2, p<.001 ; F_{2}(1,228)=45.04$, $M S E=555.1, p<.001$.
Pseudoword data The ANOVA on the lexical decision times revealed that pseudowords were responded to more rapidly when presented in lowercase than when presented in uppercase, $F_{1}(1,18)=30.64, M S E=1,472, p<.001$; $F_{2}(1,234)=36.76, M S E=8,798, p<.001$. In addition, the effect of delay was significant, $F_{1}(2,36)=11.35, M S E=$ $633, p<.001 ; F_{2}(2,468)=8.53, M S E=7,418, p<.001$. This reflected the fact that lexical decision times were shorter in the nondelay condition than when the lower part of the pseudoword was briefly delayed $(21 \mathrm{~ms}), F_{1}(1,18)=19.41, M S E=$ $562, p<.001 ; F_{2}(1,234)=14.41, M S E=7,332, p<.001$, or the upper part of the pseudoword was briefly delayed $(21 \mathrm{~ms})$, $F_{1}(1,18)=21.00, M S E=508, p<.001 ; F_{2}(1,234)=11.18$, $M S E=7,416, p<.002$. Importantly, unlike for the word data, there were no trends (less than $1 \mathrm{~ms}$ ) toward a difference between the two delayed-segment conditions, both $F_{\mathrm{s}}<1$. Finally, there were no signs of an interaction between the two factors, both $F_{\mathrm{S}}<1$.

The ANOVA on the error data revealed only a significant interaction between case and delay, $F_{1}(2,36)=5.02, M S E=$ $11.3, p<.015 ; F_{2}(2,468)=4.66, M S E=121.3, p<.02$. This interaction reflected a nonsignificant trend for an effect of delay for lowercase pseudowords, $F_{1}(2,36)=2.60, M S E=$ $17.2, p=.088 ; F_{2}(2,468)=3.02, M S E=148.2, p=.050$, but not for uppercase pseudowords, $F_{1}(2,36)=1.41, M S E=11.1$, $p=.26 ; F_{2}(2,468)=1.17, M S E=134.7, p>.30$.

The results of the present experiment are clear. First, words are responded to faster when they are briefly preceded by their upper portion than when they are briefly preceded by their lower portion, regardless of word frequency. Second, this advantage occurs for both lowercase and uppercase words, although the size of the effect is greater for lowercase than for uppercase words (see Perea et al., 2012, for a similar finding with the masked priming technique). Third, we found an overall advantage for lowercase stimuli, which was diminished for high-frequency words, thus replicating the study of Perea and Rosa (2002). And fourth, and more important, the advantage for the upper part of letter strings does not occur for pseudowords. It is important to stress here that the delayedsegment technique $i$ s sensitive to the effects with pseudowords (i.e., the nondelay condition produced shorter response times [on average, $21 \mathrm{~ms}$ ] than did the other two conditions).

As an anonymous reviewer pointed out, it is important to show that the presented findings cannot be explained as a difference in the amount of information in the upper part of words versus pseudowords. For instance, one could argue that that some letters may be more easily recognized by their upper part, whereas other letters may be more easily recognized by their lower part. Thus, it might be possible, in principle, that the letters that are more easily recognized by their upper part were more frequent in words than in pseudowords. Although the selection of materials was made independently of the manipulation, we believed that it was important to test this 
possibility. To that end, we computed the number of times each letter appeared in the materials for words and for pseudowords and conducted a test of independence. Results showed that the distribution of the letters across lexical status was approximately similar, as deduced from the value of the test, $\chi^{2}(23)=31.0$, $p>.12$; note that if we exclude the infrequent letter "ç" ( $0.39 \%$ of the letters in the experiment, and with an expected value of 5 in the chi-square test), the $p$ value was greater than .22. In other words, the distribution of the different letters across words and pseudowords is comparable. Thus, the lack of a bias for the upper part of pseudowords cannot be attributed to some uncontrolled differences between the letter distributions of words and pseudowords.

In sum, the present experiment has revealed that the advantage for the upper part of letter strings occurs for words, but not for pseudowords. This offers empirical support for the argument proposed by Blais et al. (2009) regarding the "lexical" nature of the advantage of the upper part of words. But before we examine the implications of this finding, we believe that it is important to replicate it. Experiment 2 was parallel to Experiment 1, except that we employed a new set of stimuli. In addition, given that the effects of delay were greater for lowercase words than for uppercase words, we used only lowercase stimuli.

\section{Experiment 2}

\section{Method}

Participants Twenty-four participants from the same population as that in Experiment 1 took part in the experiment $(M=$ 20.1 years, $S D=1.5$ ). None of them had participated in Experiment 1.

Materials We selected the 240 words and 240 pseudowords of five-to-seven letters employed by Perea et al. (2012). Half of these words were of high frequency $(M=119$ per million), and the other half were of low frequency $(M=11.6$ per million) (see Perea et al., 2012, for further details and the list of stimuli). The manipulation was the same as in Experiment 1, except that all the stimuli were presented in lowercase. We created three lists of counterbalanced materials.

Procedure The procedure was the same as that in Experiment 1.

Results and discussion

Incorrect responses $(4.0 \%$ and $6.1 \%$ of word and pseudoword trials, respectively) and lexical decision times less than $250 \mathrm{~ms}$ or greater than $1,500 \mathrm{~ms}$ (less than $0.9 \%$ and $3.5 \%$ of word and pseudoword trials, respectively) were excluded from the response time analyses. The mean lexical decision times for correct responses and error rates are presented in Table 2. The statistical analyses were parallel to those in Experiment 1, except for the absence of case as a factor.

Word data The ANOVA on the response times showed that, on average, response times to high-frequency words were $39 \mathrm{~ms}$ shorter than the response times to low-frequency words, $F_{1}(1,21)=105.4, M S E=523, p<.001 ; F_{2}(1$, $234)=56.67, M S E=6,303, p<.001$. The main effect of delay was also significant, $F_{1}(2,42)=35.18, M S E=588, p$ $<.001 ; F_{2}(2,468)=60.12, M S E=2,000, p<.001$. As in Experiment 1, this reflected the fact that response times to words were longer when the upper part of the letters was briefly delayed than when the lower part of the letters was briefly delayed (a 29-ms difference), $F_{1}(1,21)=29.29, M S E=$ $629, p<.001 ; F_{2}(1,234)=58.86, M S E=1,894, p<.001$. In addition, we found an advantage for the nondelay condition over the condition in which the upper part of the letters was briefly delayed (a 43-ms difference), $F_{1}(1,21)=100.67, M S E=$ $395, p<.001 ; F_{2}(1,234)=102.13, M S E=2,274, p<.001$, and the condition in which the lower part of the letters was delayed $(13 \mathrm{~ms}), F_{1}(1,21)=5.42, M S E=742, p<.03 ; F_{2}(1,234)=$ $14.43, M S E=1,831, p<.001$. The interaction between the two factors did not approach significance, both $F_{\mathrm{S}}<1$.

Table 2 Mean lexical decision times (RTs, in milliseconds; with standard deviations) and percentages of errors (ERs) for word and pseudoword targets in Experiment 2

\begin{tabular}{|c|c|c|c|c|c|c|}
\hline & \multicolumn{4}{|l|}{ Words } & \multicolumn{2}{|c|}{ Pseudowords } \\
\hline & \multicolumn{2}{|c|}{ Low Frequency } & \multicolumn{2}{|c|}{ High Frequency } & \multirow[b]{2}{*}{ RT } & \multirow[b]{2}{*}{ ER } \\
\hline & RT & ER & RT & ER & & \\
\hline No delay & $574(15)$ & $6.0(1.0)$ & $533(16)$ & $1.6(0.5)$ & $676(22)$ & 7.1(1.3) \\
\hline Delay-lower & $586(17)$ & $5.9(1.2)$ & $547(15)$ & $1.5(0.5)$ & $711(20)$ & $5.6(1.0)$ \\
\hline Delay-upper & $613(16)$ & $6.7(0.9)$ & $576(15)$ & $2.2(1.0)$ & $703(22)$ & $5.6(1.2)$ \\
\hline D.--lower vs. no delay & 12 & -0.1 & 14 & -0.1 & 35 & -1.5 \\
\hline D.--upper vs. no delay & 39 & 0.7 & 43 & 0.6 & 27 & -1.5 \\
\hline
\end{tabular}


The ANOVA on the error data reflected only a main effect of word frequency: participants committed more errors to low-frequency words than to high-frequency words, $F_{1}(1,21)=47.92, M S E=15.1, p<.001 ; F_{2}(1,234)=19.37$, $M S E=186.4, p<.001$.

Pseudoword data The ANOVA on the lexical decision times revealed that the main effect of delay was significant, $F_{1}(2,42)=24.58, M S E=333, p<.001 ; F_{2}(2,474)=31.26$, $M S E=3,258, p<.001$, which reflected the fact that lexical decision times were shorter in the nondelayed condition than in the condition in which the lower part of the pseudowords was delayed $(35 \mathrm{~ms}), F_{1}(1,21)=35.26, M S E=425, p<.001$; $F_{2}(1,237)=53.45, M S E=3,586, p<.001$, and in the condition in which the upper part of the pseudowords was delayed $(27 \mathrm{~ms}), F_{1}(1,21)=37.18, M S E=233, p<.001$; $F_{2}(1,237)=31.66, M S E=3,114, p<.001$. Finally, there was a nonsignificant 8 -ms difference between the two delayed conditions, which (if anything) go in the reverse direction to the findings with word stimuli, $F_{1}(1,21)=2.52, M S E=339$, $p>.12 ; F_{2}(1,237)=4.99, M S E=3,075, p<.03$.

The ANOVA on the error data revealed only an effect of delay, $F_{1}(2,42)=3.43, M S E=5.32, p<.05 ; F_{2}(2,474)=$ $3.13, M S E=58.3, p<.001$. This reflected a small inhibitory trend in the nondelayed condition $(1.5 \%)$, relative to both the condition in which the lower part of the pseudowords was delayed, $F_{1}(1,21)=4.29, M S E=6.4, p=.051$; $F_{2}(1,237)=4.16, M S E=65.8, p<.05$, and the condition in which the upper part of the pseudowords was delayed, $F_{1}(1,21)=7.30, M S E=3.8, p<.015 ; F_{2}(1,237)=4.70$, $M S E=58.3, p<.04$.

The present experiment successfully replicated the main finding of Experiment 1 with a new set of stimuli: The advantage of the upper part of letter strings occurred for words, but not for pseudowords. Furthermore, as in Experiment 1, this advantage was independent of word frequency.

\section{General discussion}

The results of present lexical decision experiments with a delayed-segment technique reveal a number of findings. First, response times for words preceded by their upper part are shorter than the response times to words preceded by their lower part (note that this occurred for low- and highfrequency words). Second, this advantage for the upper part of words is not restricted to lowercase words but also occurred, to a lesser degree, with uppercase words. And third, and more important, this advantage for the upper part of the letter strings was completely absent for pseudowords.

The main question at stake in the present article was whether the advantage for the upper part of words is lexical (as Blais et al., 2009, suggested) or whether the advantage occurs at the letter (letter feature) level. The results of the two experiments are clear. As in previous research (Blais et al., 2009; Perea et al., 2012), we found an advantage for the upper part of the words - this time with the delayed-segment technique. More important, we failed to obtain any signs of a parallel advantage for the upper part of the pseudowords. Given that the delayed-segment technique is sensitive to the effects for pseudowords (i.e., the baseline condition leads to shorter response times than do the two segment-delayed conditions), the most parsimonious explanation of the present data is that the advantage for the upper part of words does not occur at the letter or letter feature level but, rather, at a lexical level. Furthermore, this finding is consistent with previous evidence, which failed to find an advantage for the upper part of isolated letters (Fiset et al., 2009; Fiset et al., 2008). Thus, these findings suggest that there is no need to assign more weight to the upper part of letters in the front end of the models of visual word recognition.

What is the locus of the advantage for the upper part of letters in words? The advantage for the upper part of words is similar for low- and high-frequency words, both in the present experiments with the delayed-segment technique and in the Perea et al. (2012) experiments with the masked priming technique. If we apply the additive-factor logic method (Sternberg, 1998), this may be taken to suggest that the effect of delay in the present experiments reflects an early word-encoding processing, before word frequency starts playing a role. This is an intriguing finding, since one might have argued that in an interactive model of visual word recognition (e.g., McClelland \& Rumelhart, 1981), feedback from the word level to the letter level would benefit high- and lowfrequency words more. Indeed, there were some hints of an interaction in Experiment 1 (but not in Experiment 2), and a longer delay (e.g., $200 \mathrm{~ms}$ ) would have presumably made the interaction more apparent. A potential explanation for the observed bias for the upper part of words is that whole-word representations (not based on individual letters) are employed by the lexical system; the idea here is that that upper part of the word may provide more "whole-word" shape information than does the lower part (see, e.g., Beech \& Mayall, 2005). This option seems unlikely, though. In Experiment 1, the effect of case (i.e., the difference between uppercase and lowercase words) was greater for the infrequent words than for frequent words (see Perea \& Rosa, 2002, for a similar finding). In models that assume that lexical access can be achieved on the basis of whole-word shape (e.g., Allen, Wallace, \& Weber, 1995), the effect of case should have been greater for high-frequency words (i.e., the words that might benefit more from fast access to a "whole-word shape" route) than for low-frequency words. Furthermore, the bias for the upper part of words was not limited to the upper part of lowercase words; it also occurred, albeit to a lesser degree, for uppercase words (see also Perea et al., 2012, for a similar 
pattern of data in masked priming). Thus, on the basis of the present results, we can discard the possibility that word shape is responsible for the bias for the upper part of words (for further evidence against the "whole-word shape" hypothesis, see also Paap, Newsome, \& Noel, 1984; Pelli, Farell, \& Moore, 2003; Perea \& Rosa, 2002).

The most parsimonious account of the present findings is that the bias for the upper part of words comes from the interaction of letter representations and lexical representations. That is, although the results do depend on letter-level representations, they are evident only when these representations interact with lexical representations (see also Blais et al., 2009, for a similar proposal). A similar case occurs in the fixation locations of words versus pseudowords, as shown by Auclair and Chokron (2001): For words, fixation locations are between the beginning and middle of words (i.e., the so-called optimal viewing position), whereas this pattern of fixation location is much less clear for pseudowords. As in the present data, the effect observed for words can be partially due to the interaction of letter activation levels with stored weights between letters and words. In contrast, this effect would be absent for pseudowords, for which there are no stored representations. ${ }^{3}$ Finally, the differences between the pattern of data with lowercase and uppercase stimuli suggest that the front end of future implementations of models of visual word recognition should specify in detail how lowercase and uppercase words are processed (note that most current models of visual word recognition employ the simplified uppercase font created by Rumelhart \& Siple, 1974). Therefore, the present data can be used to constrain the parameters used by the computational models of visual word recognition once a realistic set of letter features is implemented.

At the methodological level, the delayed-segment technique may be a useful addition to the paradigms for experimentation in cognitive psychology. In experimentation on lexical access, the cognitive processes that underlie the masked priming technique and the delayed-segment techniques may be quite similar (i.e., they may tap early encoding processes). However, there is an important difference. Unlike the masked priming technique, the delayed-segment technique provides reliable effects not only for both words, but also for pseudowords. Furthermore, the delayedsegment technique is not limited to alphanumeric studies (e.g., it can be used with symbols, pictures, etc.), and it can be extended to briefly present the mid-segments versus the vertices of letters, and so forth. Finally, the delayed-segment technique may also provide useful temporal information when combined with other dependent variables (e.g., eye movements during reading, ERP waves, etc.).

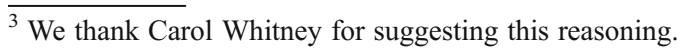

In sum, the present experiments have shown that the advantage for the upper part of letter strings in visual word recognition is specific to words; that is, it is absent for pseudowords. This dissociation implies that the "bias for the upper part of words" does not occur specifically at the letter (letter feature) level. Further research is necessary to consider in finer detail the perceptual processes involved in feature extraction during visual word recognition and reading.

Author's notes The research reported in this article has been partially supported by Grant PSI2011-26924 from the Spanish Ministry of Science and Innovation. We would like to thank Carol Whitney and two anonymous reviewers for helpful comments on a previous version of the manuscript.

\section{Appendix}

Stimuli used in Experiment 1

Low-frequency words: naipe, elite, sonda, nicotina, cacau, limbo, cinto, crude, turma, canhoto, signo, fatia, quilo, teorema, gesso, fosso, lousa, mendigo, molho, blusa, abano, sigla, vitrina, fenda, pijama, cisne, batota, milha, sucata, dieta, estante, areal, prosa, selim, mochila, civil, nuvem, degrau, dilema, padaria, canoa, caldo, cabedal, lacuna, vulto, ocaso, hipoteca, laser, isqueiro, miopia, astro, chupeta, lagarto, farsa, rocha, forro, alvor, genoma, pudim, feixe, fileira, jaula, cabina, tulipa, granizo, escada, bengala, sigilo, vindima, tigela, piada, almofada, pescada, esponja, centeio, caloiro, ficha, tenda, tecla, insecto, truque, celeiro, lenço, feitio, harpa, lagosta, cordel, emenda, berma, fruta, folia, gaveta, bicho, joelho, saliva, aprendiz, secura, bexiga, sesta, ozono, gaiola, tambor, boneca, bazar, bruma, pincel, tumulto, tesoura, indulto, beijo, alfabeto, sereia, berço, soalho, carimbo, argila, pinça, charuto, licor, freira

High-frequency words: visita, valor, filho, prova, espera, corpo, clube, general, estrada, sentido, norte, moeda, serviço, sector, verdade, corrida, doença, viagem, modelo, falta, futuro, greve, origem, sinal, prazo, metade, filme, cultura, acesso, imprensa, futebol, pessoa, tribunal, volta, emprego, bairro, droga, canal, imagem, assunto, coisa, morte, proposta, atitude, escola, ideia, energia, economia, risco, autor, ambiente, produto, tarde, mulher, curso, linha, aumento, texto, gente, total, palco, estudo, partida, clima, etapa, crime, defesa, idade, crise, ensino, livro, preço, amigo, justiça, desejo, teatro, regime, entrada, debate, plano, efeito, terra, fonte, medida, jeito, festa, maneira, fundo, revista, palavra, volume, artigo, margem, centro, favor, disco, procura, força, sucesso, venda, jogador, vinho, jornada, cinema, senhor, vontade, quadro, ciclo, igreja, ponte, cabeça, queda, cimeira, oferta, lista, carta, campo, chefe, papel, ritmo 
Pseudowords: tudeza, fongo, rugua, tulho, crodito, siscurso, tolsa, lanro, congumo, cilto, tuivo, vecio, mibra, eslera, memaria, excelto, lecanto, enjado, nomingo, cotum, tarba, viteria, nelva, decibuis, luleta, vrego, foura, rarada, tazigo, amelo, floro, esgolha, lusba, anico, dilicil, tevor, torte, fisel, tavia, guavida, insia, cerfo, pecorde, funto, calela, luxidia, jovilho, aloto, pubtil, baslo, bireita, astecia, jonsola, larna, suculo, purfa, atanha, jalha, vigerio, darca, voreno, ludor, mospra, lequena, toraz, fucil, drecha, faupa, falanha, teita, ababada, lobina, zasca, brete, dietel, eucopeu, tatulo, rerreno, paber, funhal, apoca, hente, areus, etiste, deminio, dalar, prave, firura, troda, litagre, doenva, agril, ateno, aciva, vrimo, plecha, tinheta, alaque, pomedou, pripel, conlinua, ferlor, famolia, saeda, tomeça, itimico, reral, vapaz, alinal, resjosta, redio, nolar, capor, utolia, tassada, tobra, lesta, catelo, carno, voldo, ganco, macura, pogina, dendo, motua, arporedo, pepigo, manhe, nousea, berrota, esluta, nolha, uvido, tarque, polecia, terve, lanto, timples, areta, runco, zeste, mausoliu, azirma, diulogo, quarte, flotal, aquete, loiva, redido, lecto, ramina, rotivo, redida, bidel, tonvade, togro, tovem, laide, inimo, aneno, urrita, itrio, flaro, injaria, raterno, polotico, alpuma, tultado, cavico, tarna, letado, catino, zista, dierio, parço, louto, umbito, anfiga, baifo, rauta, autarda, pentro, pevucato, tinve, alcar, notucia, axido, logrima, fembro, pamar, protica, alguim, dirla, losto, vatima, alonea, esvoto, pirpura, anaba, tonge, mesica, sibado, crova, madutino, jelha, timbo, pregito, alius , detadona, chaza, inrenso, azitude, frime, domanio, vorreia, vunto, tobel, langria, cucha, mestla, tonzonal, vipita, ceito, laquete, modia, pencral, surie, etlas, saide, dilial, tivil, jarto, reica, zusso, sovel, afosto, caperna, lader, zorrida, tordomo

\section{References}

Allen, P. A., Wallace, B., \& Weber, T. A. (1995). Influence of case type, word frequency, and exposure duration on visual word recognition. Journal of Experimental Psychology. Human Perception and Performance, 21, 914-934.

Auclair, L., \& Chokron, S. (2001). Is the optimal viewing position in reading influenced by familiarity of the letter string? Brain and Cognition, 46, 20-24.

Beech, J. R., \& Mayall, K. A. (2005). The word shape hypothesis reexamined: Evidence for an external feature advantage in visual word recognition. Journal of Research in Reading, 3, 302-319.

Blais, C., Fiset, D., Jolicoeur, P., Arguin, M., Bub, D. N., \& Gosselin, F. (2009). Reading between eye saccades. PLoS One, 4(7), e6448. doi:10.1371/journal.pone.0006448

Carreiras, M., Gillon-Dowens, M., Vergara, M., \& Perea, M. (2009). Are vowels and consonants processed differently? ERP evidence with a delayed letter paradigm. Journal of Cognitive Neuroscience, 21, 275-288

Coltheart, M., Rastle, K., Perry, C., Ziegler, J., \& Langdon, R. (2001). DRC: A dual-route cascaded model of visual word recognition and reading aloud. Psychological Review, 108, 204-256.
Davis, C. J. (2010). The spatial coding model of visual word identification. Psychological Review, 117, 713-758.

Fiset, D., Blais, C., Arguin, M., Tadros, K., Éthier-Majcher, C., Bub, D., \& Gosselin, F. (2009). The spatio-temporal dynamics of visual letter recognition. Cognitive Neuropsychology, 26, 23-35.

Fiset, D., Blais, C., Éthier-Majcher, C., Arguin, M., Bub, D., \& Gosselin, F. (2008). Features for identification of uppercase and lowercase letters. Psychological Science, 19, 1161-1168.

Forster, K. I. (1998). The pros and cons of masked priming. Journal of Psycholinguistic Research, 27, 203-233.

Forster, K. I., \& Davis, C. (1984). Repetition priming and frequency attenuation in lexical access. Journal of Experimental Psychology: Learning, Memory, and Cognition, 10, 680-698.

Forster, K. I., \& Forster, J. C. (2003). DMDX: A Windows display program with millisecond accuracy. Behavior Research Methods, Instruments, \& Computers, 35, 116-124.

Grainger, J., \& Jacobs, A. M. (1996). Orthographic processing in visual word recognition: A multiple read-out model. Psychological Review, 103, 518-565.

Huey, E. B. (1968). The psychology and pedagogy of reading. Cambridge, MA: MIT Press (Original work published 1908).

Lee, H.-W., Rayner, K., \& Pollatsek, A. (2001). The relative contribution of consonants and vowels to word identification during reading. Journal of Memory and Language, 44, 189-205.

Lee, H.-W., Rayner, K., \& Pollatsek, A. (2002). The processing of consonants and vowels in reading: Evidence from the fast priming paradigm. Psychonomic Bulletin \& Review, 9, 766-772.

McClelland, J. L., \& Rumelhart, D. E. (1981). An interactive activation model of context effects in letter perception: Part 1. An account of basic findings. Psychological Review, 88, 375-407.

Paap, K. R., Newsome, S. L., \& Noel, R. W. (1984). Word shape's in poor shape for the race to the lexicon. Journal of Experimental Psychology. Human Perception and Performance, 10, 413-428.

Pelli, D. G., Farell, B., \& Moore, D. C. (2003). The remarkable inefficiency of word recognition. Nature, 423, 752-756.

Perea, M., Comesaña, M., Soares, A. P., \& Moret-Tatay, C. (2012). On the role of the upper part of words in lexical access: Evidence with masked priming. Quarterly Journal of Experimental Psychology. doi:10.1080/17470218.2011.636151

Perea, M., Gomez, P., \& Fraga, I. (2010). Masked nonword repetition effects in yes/no and go/no-go lexical decision: A test of the evidence accumulation and deadline accounts. Psychonomic Bulletin \& Review, 17, 369-374.

Perea, M., \& Rosa, E. (2002). Does "whole word shape" play a role in visual word recognition? Perception \& Psychophysics, 64, 785-794.

Pollatsek, A., \& Well, A. D. (1995). On the use of counterbalanced designs in cognitive research: A suggestion for a better and more powerful analysis. Journal of Experimental Psychology: Learning, Memory, and Cognition, 21, 785-794.

Rumelhart, D. E., \& Siple, P. (1974). The process of recognizing tachistoscopically presented words. Psychological Review, 81, 99-118.

Soares, A. P., Comesaña, M., Iriarte, A., Almeida, J. J., Simões, A., Costa, A., . . Machado, J. (2010). P-PAL: Uma base lexical com índices psicolinguísticos do Português Europeu [P-PAL: A European Portuguese lexical database]. Linguamática, 2, 67-72.

Sternberg, S. (1998). Discovering mental processing stages: The method of additive factors. In D. Scarborough \& S. Sternberg (Eds.), Methods, models, and conceptual issues: An invitation to cognitive science (pp. 703-863). Cambridge, MA: MIT Press.

Wechsler, H. B., \& Bell, A. (2005). Speed reading for professionals. Hauppauge, NY: Barron's Business Success Guides. 